\title{
COMBINED MAMMOGRAPHIC AND SONOGRAPHIC EVALUATION OF PALPABLE BREAST MASS
}

\author{
Muna Badu', Rabindra Simkhada ${ }^{2}$
}

\begin{abstract}
INTRODUCTION: Detection and evaluation of breast mass is challenging. Identification of malignancy in earliest possible stage is rewarding. Several radiological diagnostic modalities are available for this purpose including mammography and ultrasonography. The objective of the study was to evaluate the accuracy of mammography and ultrasonography individually and in combination to detect and characterize palpable breast mass and to correlate the imaging findings with histopathology.
\end{abstract}

MATERIAL AND METHODS: Patients presented with palpable breast lump were examined prospectively. All patients were examined by both mammography and ultrasonography. Fine needle aspiration cytology was done for all findings. Correlations of mammography and ultrasonography findings were done with histopathology.

RESULTS: A total of 42 patients were evaluated. Fine needle aspiration cytology revealed $30(71.42 \%)$ benign and 12 $(28.58 \%)$ malignant lesions. The sensitivity and specificity for mammography were $83.33 \%$ and $93.33 \%$ and for ultrasonography were $81.81 \%$ and $90.32 \%$ respectively. When findings of mammography and ultrasonography were combined, both sensitivity and specificity were increased to $91.66 \%$ and $96.66 \%$ respectively.

CONCLUSION: Combined mammography and ultrasonography had higher sensitivity and specificity rate than sensitivity and specificity rate observed for either of single modality. This study suggests that any patient who is advised to go for a single modality of investigation should rather be investigated using the combined modality.

KEYWORDS: Breast Mass; Mammogram; Ultrasonography

1. Lecturer, Department of Radiology, Kathmandu Medical College, Kathmandu Nepal

2. Associate Professor, Division of Cardiology, Universal College of Medical Sciences, Bhairahawa, Nepal

\author{
For Correspondence \\ Dr. Muna Badu \\ Lecturer, \\ Department of Radiology \\ Kathmandu Medical College, Kathmandu, Nepal \\ E-mail: muna.badusimkhada@gmail.com
}




\section{INTRODUCTION}

Detection and evaluation of breast mass is one of the rewarding areas of radiology. Success in these endeavors depends upon the ability to perceive a possible abnormality, the skill to evaluate it with appropriate investigations like mammogram (MG) and ultrasonography. The goal is to detect breast cancer at the earliest possible stage yet to keep unnecessary biopsies to minimum. ${ }^{1}$

Mammography is one of the commonly used $1^{\text {st }}$ line diagnostic investigation for breast mass. Other commonly available investigations like ultrasound is also being used widely for the same.

The traditional role for ultrasound (USG) in breast imaging has been as an adjunct to mammography, mainly differentiating cystic from solid masses. However its use has expanded including screening for malignancy, characterization of benign and malignant masses, localregional staging, and monitoring response to therapy. In addition, USG has real time capability, making the preferred modality for guiding interventional procedures. ${ }^{2}$ Breast lesions that are initially identified on mammography can be further characterized with ultrasonography. Ultrasound can assist in identifying whether the mammographically detected calcifications are associated with invasive component. When ultrasonography is used to further evaluate mammographic findings, accurate mammographicultrasonographic correlation is required.

Ultrasound is commonly used as a "secondary test" or as an adjunct to mammography. ${ }^{4}$ In most practices with qualified personnel, sonography is the preferred modality for guiding percutaneous biopsies of suspicious breast masses." Sonography often serves as "an extra view," providing information in addition to spot compression, magnification, rolled, or tangential mammographic views.

The definitive test for the determination of nature of breast lump is histopathology. This study is aimed to evaluate the effectiveness of MG and USG in the diagnosis of breast lump individually and in combination to histopathology as a gold standard test.

\section{MATERIALAND METHODS}

This was a hospital based prospective, comparative study conducted at the department of Radiology from August 2013 to July 2014. The study was conducted after the approval of ethical committee. Patients had to have age more than 30 years of age, clinically palpable mass to be enrolled. Patients referred for screening of breasts, pregnant females with breast lump, patients who refuse to give consent, and whose histopathology report couldn't be traced were excluded. Informed consent was obtained from each patient before enrolling them in the study.

History was taken and relevant examinations were done. The participants underwent both MG and USG examination. MG was performed with GE healthcare ALPHA ST mammography machine. Two view of each breast were obtained, craniocaudal and mediolateral oblique. USG was performed with GE healthcare LOGIC Q6 PRO ultrasound machine. This was followed by USG guided FNAC examination. The specimens were sent for the histopathology examination. Statistical analyses were done using statistical package for social studies software (SPSS) version 17 for windows. Frequencies and percentage distribution were obtained for applicable variables. Univariate analysis of different variables of MG and USG to the histological findings were done using chi square test. $\mathrm{P}$ value was calculated and value $<0.05$ were considered significant. Specificity and sensitivity of MG and USG individually and in combination to determine the nature of breast lump in relation to histopathological findings as gold standard were calculated.

\section{RESULTS}

A total of 42 female participants with palpable breast lump were included in this study. The age of the participants ranged from 30-67 years. The mean age was $39.64 \pm 10.23$ years. Mean age for benign lesion was $36.47 \pm 7.93$ years and for malignant was $47.58 \pm 11.31$ years. A total of $30(71.43 \%)$ had noticed lump for less than 2 months of duration. Pain and discharge was present in $8(19.04 \%)$ and $4(9.52 \%)$ of participants respectively. The clinical characteristics of enrolled subjects are shown in table 1.

Table 1: Clinical Characteristics of participants.

\begin{tabular}{|l|l|l|l|}
\hline Characteristics & Frequency & Percentage \\
\hline \multirow{2}{*}{$\begin{array}{l}\text { Duration } \\
\text { of lump }\end{array}$} & $<2$ months & 30 & $71.43 \%$ \\
\cline { 2 - 4 } & $2-18$ months & 10 & $23.80 \%$ \\
\cline { 2 - 4 } & $>18$ months & 2 & $4.77 \%$ \\
\hline Pain & 8 & $19.04 \%$ \\
\hline Discharge & 4 & $9.52 \%$ \\
\hline Fever & 2 & $4.76 \%$ \\
\hline Weight loss & 0 & $0 \%$ \\
\hline Family history & 2 & $4.76 \%$ \\
\hline
\end{tabular}

In $36(85.72 \%)$, masses were found in upper outer quadrant and in $2(4.76 \%)$ cases each, it was in upper inner and lower outer quadrants . In $41(97.62 \%)$ cases, the breast masses were unilateral and only $1(2.38 \%)$ was bilateral. Most of the lesions were single and only $1(2.38 \%)$ was multiple. Characteristics of breast mass is summarized in table 2 .

\section{Table 2: Characteristics of breast mass}

\begin{tabular}{|l|l|l|l|}
\hline Characteristics & Frequency & Percentage \\
\hline Site of lesion & Upper outer quadrant & 36 & $85.72 \%$ \\
\cline { 2 - 4 } & Upper inner & 2 & $4.76 \%$ \\
\cline { 2 - 4 } & Lower outer quadrants & 2 & $4.76 \%$ \\
\cline { 2 - 4 } & Lower inner & 0 & 0 \\
\cline { 2 - 4 } & Retroaerolar & 2 & $4.76 \%$ \\
\hline \multirow{4}{*}{ Multerality } & Unilateral & 41 & $97.62 \%$ \\
\cline { 2 - 4 } & Bilateral & 1 & $2.38 \%$ \\
\hline & Single & 41 & $97.62 \%$ \\
\cline { 2 - 4 } & Multiple & 1 & $2.38 \%$ \\
\hline
\end{tabular}


A total of $38(90.47 \%)$ lesions had increased density in mammogram and $2(4.76 \%)$ had decreased or mixed density. The shape of lesion in mammogram were, oval in 14 $(33.33 \%)$, round $15(35.71 \%)$, irregular $13(30.95 \%)$ and lobular 0 . The margin of lesion were circumscribed in 27 $(64.28 \%)$, irregular in $4(9.52 \%)$, spiculated in $8(19.04 \%)$, and diffuse in $3(7.14 \%)$ There was no calcification in 22 $(52.38 \%)$, microcalcification in $4(9.52 \%)$, and macrocalcification in $16(38.09 \%)$, lesions. Among all participants, mammogram showed surrounding halo in 28 $(66.66 \%)$ number of cases. A total of $21(50 \%)$ had type II breast parenchyma, followed by type I and III in $10(23.80 \%)$. Skin thickening over lesion was present in $4(9.52 \%)$. Distortion of the fibroglandular tissues was present in 9 $(21.42 \%)$. A total of 27 (64.28\%) cases were falling into breast imaging reporting and data system (BIRADS) II, followed 10 $(23.80 \%)$ into BARDIS V .A total of $2(4.76 \%)$ patients had BARDIS III and IV score. One $(2.38 \%)$ case had normal mammogram.

Ultrasound breast revealed $41(97.61 \%)$ of lesions to be hypoechoic and only $1(2.38 \%)$ with mixed echogenicity. Margin of lesion in ultrasound showed $31(73.80 \%)$ of the cases well defined followed by $6(14.28 \%)$ with spiculated margins. Irregular and diffuse margin were seen in $3(7.14 \%)$ and $2(4.76 \%)$ cases respectively. Ultrasound revealed calcification in $17(40.47 \%)$ cases only. Similarly skin infiltration was present in $3(7.14 \%)$. Internal echoes in breast masses were present in $18(42.85 \%)$. A total of $4(9.52 \%)$ cases had posterior enhancement. Post acoustic shadow was present in $11(26.19 \%)$. Seven $(16.66 \%)$ out of 42 cases had increased color flow in Doppler studies. Ultrasound revealed significant lymphadenopathy in $4(9.52 \%)$ cases.

Among the total participants, USG diagnosed $31(73.80 \%)$ as benign and $11(26.19 \%)$ as malignant. Mammography diagnosed $30(71.42 \%)$ as benign and $12(28.57 \%)$ as malignant. Histopathology showed Fibro adenoma in 16 $(38.09 \%)$ cases, which was the commonest lesion followed by malignant lesions in $12(28.57 \%)$. The histopathological findings are shown in table 3 .

Table 3: Different types of breast lesions seen in participants

\begin{tabular}{|l|l|l|}
\hline Diagnosis & No. of cases & Percentage \\
\hline Fibroadenoma & 16 & $38.09 \%$ \\
\hline Malignancy & 12 & $28.57 \%$ \\
\hline Fibrocystic changes & 4 & $9.52 \%$ \\
\hline Lipoma & 3 & $7.14 \%$ \\
\hline Galactocele & 2 & $4.76 \%$ \\
\hline Granulomatous disease & 2 & $4.76 \%$ \\
\hline Fat necrosis & 1 & $2.38 \%$ \\
\hline Breast abscess & 1 & $2.38 \%$ \\
\hline Papilloma & 1 & $2.38 \%$ \\
\hline Total & 42 & $100 \%$ \\
\hline
\end{tabular}

Considering histopathological findings as gold standard, Ultrasound had $81.81 \%$ sensitivity and $90.32 \%$ specificity where as mammogram had $83.33 \%$ and $93.33 \%$ sensitivity and specificity respectively. When combined, both sensitivity and specificity of diagnosing malignant lesions increased up to 91.66 and $96.66 \%$ respectively.

Correlation of individual components of mamographic and USG findings with nature of the lesion (benign vs malignant), revealed significant positive correlation with some but not with all the factors, which is shown in table 4 and table 5 respectively.

Table 4: Correlation of type of breast mass (benign versus malignant) with mammographic variables

\begin{tabular}{|l|l|}
\hline Mammographic variables & P value \\
\hline Density & $>0.05$ \\
\hline Shape & $>0.05$ \\
\hline Margin & $<0.01$ \\
\hline Calcification & 0.04 \\
\hline Halo & 0.03 \\
\hline Breast pattern & $<0.01$ \\
\hline Skin thickening & $>0.05$ \\
\hline Fibroglandular architectures & $<0.01$ \\
\hline BIRADS & $<0.01$ \\
\hline
\end{tabular}

Table 5: Correlation of type of breast mass (benign versus malignant) with sonographic variables

\begin{tabular}{|l|l|}
\hline Sonographic variables & P value \\
\hline Echogenicity of lesion & $>0.05$ \\
\hline Margin & $<0.01$ \\
\hline Calcification & $>0.05$ \\
\hline Skin infiltration & $>0.05$ \\
\hline Internal echoes & 0.04 \\
\hline Posterior enhancement & $>0.05$ \\
\hline Posterior acoustic shadow & $<0.01$ \\
\hline Color flow & 0.14 \\
\hline Lymph node & 0.004 \\
\hline
\end{tabular}

\section{DISCUSSION}

This cross sectional study was carried out with an aim to evaluate the accuracy of mammography and ultrasound individually and in combination to detect and characterize palpable breast mass with cytopathological correlation.

The mean age was $39.64 \pm 10.23$ years. Mean age for benign lesion was lower (36.47 \pm 7.93 years) compared to malignant $(47.58 \pm 11.31$ years $)$. This finding is in consistence with published literatures.

The breast lesions were more common in upper and outer quadrant. The high proportion of upper outer quadrant carcinomas of the breasts is a reflection of the greater amount of breast tissue in this quadrant. There was no significant correlation of the quadrant with type of lesion. Andrew H.S. Lee showed similar proportions of lesions in this quadrant.

A total of $38(90.47 \%)$ of lesion had increased density. As a solitary feature in lesion analysis, mammographic density is difficult to assess and is limited value for the prediction of the benign and malignant nature of non calcified breast masses as described by Jackson et al. ${ }^{8}$ In this study also, there was no significant correlation of breast density with breast malignancy ( $\mathrm{p}$ value $>0.05$ ). 
In the present study, most of the benign lesions had well defined margins. Liberman $\mathrm{L}$ et al. reported that benign mass has morphological appearance showing well defined margins $(98 \%)$ and round or oval shape. ${ }^{9}$ In the literature, margin is regarded as one of the most important feature to differentiate benign and malignant breast lesions. In this study also, margin was statistically significant for malignancy $(p$ value $<0.05)$.

Calcifications were seen in 20 cases in this study. Among them 16 had macrocalcifications $(38.1 \%)$ and only $4(9.52 \%)$ cases had micro calcifications. Macro calcifications were seen commonly in benign lesions where as micro calcifications were seen in malignant cases. Gary J Whiteman et al found that benign calcifications are typically more common, larger, coarser and more easily identifiable than malignant calcifications in mammography. Malignant calcifications are characteristically pleomorphic or heterogeneous and appear as irregular, linear, branching or granular forms..$^{10}$ In this study microcalcifications detected on mammography were associated with malignancy and macrocalcifications with benign lesions ( $p$ value $<0.01$ ), however calcifications and malignancy had no significance in ultrasonographic findings ( $p$ value $>0.05$ )

A total of $9(21.42 \%)$ of participants had architectural distortion and all had malignancy in histopathology. Shaheen $\mathrm{R}$ et al. described architectural distortion as the third mostcommon appearance of breast cancer. In this study there was strong correlation between architectural distortion and malignancy $(p$ value $<0.01)$.

Posterior enhancement was noted in $4(9.52 \%)$. It did not show any significant correlation with histopathology. There are several published literatures with variable results. Out of 12 malignant cases, 4 cases had lymphadenopathy. None of the benign lesions had enlarged lymph nodes. Whenever lymphadenopathy was present, it was highly significant for malignancy ( $p$ value $<0.05$ ).

The sensitivity and specificity of mammography was $83.33 \%$ and $93.33 \%$ respectively. McCavert $M$ et al found mammography to be more sensitive in patients over 50 years compared with those patients less than 50 years. With the increase of fibro glandular density the level of sensitivity with mammography decreases. ${ }^{12}$ Findings of this study is similar to literatures.

The sensitivity and specificity of sonography were $81.81 \%$ and $90.32 \%$ respectively. Candelaria RP et al found that breast ultrasound plays a major role in the identification, diagnosis, and staging of breast cancer. ${ }^{13}$ Malik $\mathrm{G}$ et al. found sensitivity of sonomammography was more for benign $92 \%$ than malignant lesions $67 \%$, and its specificity was high for malignant lesions $(92.4 \%){ }^{14}$

When findings of MG and USG were combined, both sensitivity and specificity were increased to $91.66 \%$ and $96.66 \%$ respectively. Only one patient with palpable lump had both a mammogram and ultrasound reported as normal in which subsequent histology revealed a carcinoma.

Zonderland HM et al found the sensitivity of mammography for all 4,811 cases was $83 \%$, the specificity was $97 \%$. After USG, the combined sensitivity increased to $91 \%$, with a specificity of $98 \%$. Its contribution to the diagnosis of breast cancer in their study was $7.4 \% .{ }^{15}$ Shetty MK et al. found sensitivity (14 of 14) and negative predictive value (186 of 186) for a combined mammographic and sonographic assessment were $100 \%$ and the specificity was $80.1 \%$ (186 of 232). Combined mammographic and sonographic assessment was shown to be very helpful in identifying benign as well as malignant lesions causing palpable abnormalities of the breast. $^{16}$ The sensitivity and specificity of combined MG and USG, seen in this study was comparable to the published literatures. Combined diagnostic modality yielded better sensitivity and specificity as compared to individual test.

\section{CONCLUSION}

Combined MG and USG had higher sensitivity and specificity rate than sensitivity and specificity rate observed for either single modality. A combined MG and USG approach to detect breast diseases was significantly more helpful in accurate evaluation of breast pathologies than when either modality was used alone. Therefore, we suggest combined modality of investigations for evaluation of breast mass. 


\section{REFERENCES}

1. Feig SA. Breast masses. Mammographic and sonographic evaluation. Radiol Clin North Am. 1992 Jan;30(1):67-92. PMid:1732936

2. Fornage BD, Edeiken-Monroe BS. Breast sonography. In:Hunt KK, Robb GL, Strom EA, Ueno NT, editors. Breast cancer.2nded. New York: Springer, 2008. p. 121-61. http://dx.doi.org/10.1007/978-0-387-34952-7_5

3. Whitman GJ, Arribas E, Uppendahl L. Mammographicsonographic correlation. Semin Roentgenol. 2011 Oct;46(4):252-9.

http://dx.doi.org/10.1053/j.ro.2011.08.003

PMid:22035667

4. Gordon PB. Ultrasound for breast cancer screening and staging. Radiol Clin North Am. 2002 May;40(3):431-41. http://dx.doi.org/10.1016/S0033-8389(01)00014-8

5. Gordon PB, Goldenberg SL, Chan NH. Solid breast lesions: diagnosis with US-guided fine needle aspiration biopsy. Radiology. 1993 Nov;189(2):573-80.

http://dx.doi.org/10.1148/radiology.189.2.8210392 PMid:8210392

6. Parker SH, Jobe WE, Dennis MA, Stavros AT, Johnson KK, Yakes WF, Truell JE, Price JG, Kortz AB, ClarkDG. USguided automated large-core breast biopsy. Radiology. 1993May;187(2):50711.http://dx.doi.org/10.1148/radiolo gy.187.2.8475299 PMid:8475299

7. Andrew HSL. Why is carcinoma of the breast more frequent in the upper outer Quadrant? A case series based on needle core biopsy diagnoses. Breast. 2005; Apr14(2):151-2.

8. Jackson VP. Diagnostic importance of the radiographic density of non calcified breast masses:analysis of 91 lesions. AJR1991;July 157(1) :25-8.

9. Liberman L, Feng TL, Susnik B. Case 35: intracystic papillary carcinoma with invasion. Radiology. 2001 Jun;219(3):781-4.

http://dx.doi.org/10.1148/radiology.219.3.r01jn10781

PMid:11376269
10. Whitman GJ, Stephens TW, Hopkins K. Benign and malignant breast calcifications. Contemp Diagn Radiol. 2002.25:1-6.

11.Shaheen R, Schimmelpenninck CA, Stoddart L, Raymond $H$, Slanetz PJ. Spectrum of diseases presenting as architectural distortion on mammography: multimodality radiologic imaging with pathologic correlation. Semin Ultrasound CTMR. 2011 Aug;32(4):35162.http://dx.doi.org/10.1053/j.sult.2011.03.008 PMid:21782125

12. McCavert M, O'Donnell ME, Aroori S, Badger SA, Sharif $M A$, Crothers JG, Spence RA. Ultrasound is a useful adjunct to mammography in the assessment of breast tumours in all patients. Int JClin Pract. 2009

Nov;63(11):1589-94.

http://dx.doi.org/10.1111/j.1742-1241.2009.02102.x PMid:19686337

13. Candelaria RP, Hwang L, Bouchard RR, Whitman GJ. Breast ultrasound: current concepts. Semin Ultrasound CT MR. 2013 Jun;34(3):213-25.

http://dx.doi.org/10.1053/j.sult.2012.11.013

PMid:23768888

14. Malik G, Waqar F, Buledi GQ. Sonomammography for evaluation of solid breast masses in young patients. J Ayub Med Coll Abbottabad. 2006 Apr-Jun;18(2):34-7. PMid:16977811

15. Zonderland HM, Coerkamp EG, Hermans J, Vande Vijver $M J$, Van Voorthuisen AE. Diagnosis of breast cancer: contribution of US as an adjunct to mammography. Radiology 1999; 213:41322.

http://dx.doi.org/10.1148/radiology.213.2.r99nv05413 PMid:10551221

16. Shetty MK, Shah YP, Sharman RS. Prospective evaluation of the value of combined mammographic and sonographic assessment in patients with palpable abnormalities of the breast. JUltrasound Med 2003; 22:2638. http://dx.doi.org/10.1016/s0301-5629(03)00402-2 